\title{
The relationship between institutions and value creation in software development models
}

\author{
Arabella Mocciaro Li Destri \\ Department of Economics, Management and Statistics, University of Palermo, \\ Palermo, Italy, and \\ Giovanna Lo Nigro \\ Department of Industrial and Digital Innovation, University of Palermo, \\ Palermo, Italy
}

\section{Software development models}

Received 22 November 2016 Revised 8 September 2017 3 November 2017 Accepted 8 November 2017

\begin{abstract}
Purpose - The purpose of this paper is to analyse the possibility for firms to consider institutional settings to systematically direct dispersed individual efforts of discovery and invention towards objects (products or processes) of their interest in order to enhance their value creation capacity.

Design/methodology/approach - The authors conduct a comparative analysis of the different institutional settings within which software products are invented and produced - closed producer-centred model, open user-centred model, and hybrid interactive producer-user model.

Findings - The authors draw indications regarding the possibility to design institutional settings for value creation and the potential pitfalls tied to these strategic tools.

Originality/value - A theoretical framework is elaborated in order to understand the different ways in which institutional contexts influence and direct value creation processes. The model analysed shows the firms' deliberate attempt to stimulate a dynamic process of social interaction and communication which may foster higher levels of creativity and innovation. In order to guarantee the necessary accessibility and to sufficiently motivate external programmers towards the perception of a new code, the firm has to surrender the traditional source through which it appropriates value: barriers to the accessibility of the code developed through IPRs. The adoption of an institutional setting which facilitates dynamic value creation processes suggests, therefore, the need to turn to dynamic mechanisms for value appropriation in parallel.
\end{abstract}

Keywords Institution, Value creation, Software development model

Paper type Research paper

\section{Introduction}

Strategy literature distinguishes value creation from value appropriation processes (Mocciaro Li Destri and Dagnino, 2005; Lepak et al., 2007). The former process entails the creation of new sources of competitive advantage through innovation: it consists on the intuition and implementation of new resource combinations or the development of new competences or knowledge able to elevate the level of efficiency within the economic system considered. Value appropriation, on the other hand, regards the issues of exploiting and maintaining specific sources of competitive advantages and entails the capacity to obtain rents from transactions, given a specific set of resources and of capabilities and the way these are combined.

In the strategic literature, apart from a few exceptions, institutions have sometimes been overlooked completely, alternatively they have been considered exogenously determined by

(C) Arabella Mocciaro Li Destri and Giovanna Lo Nigro. Published in the European Journal of Management and Business Economics. Published by Emerald Publishing Limited. This article is published under the Creative Commons Attribution (CC BY 4.0) licence. Anyone may reproduce, distribute, translate and create derivative works of this article (for both commercial and non-commercial purposes), subject to full attribution to the original publication and authors. The full terms of this licence may be seen at http://creativecommons.org/licences/by/4.0/legalcode

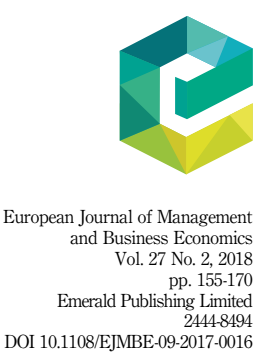


EJMBE

27,2

156 governments or evolutionary paths. In the latter case, institutions represent a set of given variables that must be considered (explicit or implicit) during decision-making processes. More seldom, however, is the analysis of firms' active influence on institutional contexts, while we find some notable examples in unorthodox economics (North, 1994; Nelson, 1998).

This paper contends that firms can design and manage institutional mechanisms strategically, not only to appropriate value, but also to enhance their capacity to create value.

Institutions have been the focus of studies in areas of intellectual endeavour which range from politics to sociology; they have been discussed from the very different perspective and this is the reason they have found multiple definitions (Hodgson, 1998a). In the present paper, the notion of institutional contexts derives from the neo-institutional approach in economic studies (Polanyi, 1957; North and Thomas, 1973; North, 1990, 1994, 1998; Heiner, 1983, 1986; Langlois, 1984, 1986a, b, c, 1992a, b, 1995; Loasby, 1983, 1986, 1994, 1998; Hodgson, 1998a, b). As such, they include all rules and norms which lead to behavioural regularities as well as their enforcement mechanisms. In this perspective, the rules, the norms and the enforcement mechanisms considered may have a formal or an informal nature; therefore, institutions range from commercial and tax laws, property rights and contracts, to social habits, cultures and ideologies. In brief, institutions may be considered as "the rules of the game in a society or [...] the constraints men have defined in order to discipline their relationships" (North, 1990, p. 23). The institutional context is, therefore, the structure within which economic and social interactions take place. These social interaction mechanisms are based on processes which involve feedback from the cumulative results of individual actions, and thereby are capable of achieving substantial coordination and coherence in the collective performance of the ensemble of distributed agents.

The economic historian and Nobel laureate Douglass North $(1990,1991,1994,1998)$ has shown that institutions are relevant in economic analyses because they create inefficiencies within the system that distort the final outcomes obtained by economic agents operating within the system itself. Institutions, for example, define the incentives that guide economic endeavour and create partial rigidities to the flow of tangible and intangible resources within economic systems. Consequently, in the present analysis regarding value creation processes, this approach points to the potential role of such institutions as a source of systematic influence directing individual efforts of discovery and invention.

Throughout history, government agents have continuously designed institutions which aim to create incentives towards goals considered coherent with the nation's interest. Amongst the typical institutional mechanisms used in capitalistic economic systems to motivate entrepreneurs and firms towards the intuition and execution of new resource combinations (or, in other terms, to create value), the most notable are the various forms of intellectual property rights (IPRs) - which include patents, copyrights and industrial secrets. Essentially, these mechanisms are aimed to motivate economic agents to create value for the society they belong to, by consenting that the success or failure of their endeavours influences them more than proportionately.

Consistently, the efficacy of typical IPRs to consent the protection of rent flows from new resource combinations once they have been created (i.e. value appropriation) has often been analysed. Furthermore, typical IPRs are designed to enhance producer-centred innovation processes, while they were not designed to enable user-centred innovation processes which leverage the creativity dispersed in various levels of the external environment. As a consequence, while the efficacy of typical IPRs to enhance producer-centred innovation is often debated, their capacity to spur user-centred innovation processes is far less debated.

Both the focus on the capacity to guarantee value appropriation from innovations and the central role accorded to producer-centred innovation, are (implicit) consequences of having viewed the innovation process in Schumpeterian linear terms. However, following North's studies regarding the economic role of institutions, the way in which IPRs are designed also 
influences the social dynamics underlying value creation processes. Furthermore, numerous authors have underscored the importance of communication, learning and social interaction both within the single organisation and between the firm and its environment for innovation to take place (Chatterji and Fabrizio, 2014; Von Hippel, 1976, 1988, 1994; Allen, 1983; Nonaka, 1988; Heller and Eisenberg, 1998; Merges and Nelson (1994); Brown and Eisenhardt, 1995; Jeppesen and Lakhani, 2010; Afua and Tucci, 2012; Meynhardt et al., 2016).

Departing from different logical bases, Hayek (1945, 1948a, 1948b, 1960, 1978), Von Hippel $(1976,1988,1994)$ and Von Hippel and Von Krogh (2003) argued that due to the fact that the knowledge on which they rest is tacit, private and empirical, the sources of creativity underlying value creation processes are inevitably dispersed throughout the economic system as market mechanisms fail to consent their transfer. These studies, along with those mentioned above regarding the role of social interaction and communication for innovation processes, have been conducted to recognise that, within firm development, a fundamental part of the knowledge and creative effort underlying the process of value creation is often dispersed both within the organisation (and not necessarily restricted to the $\mathrm{R} \& \mathrm{D}$ lab) and in the external context. Thus, the interest matured lately in the formulation of open innovation models is not surprising (Chesborough, 2003; Chesborough and Appleyard 2007; Tuomi, 2002; Baldwin and Von Hippel 2011; Piller and West, 2014).

In this vein, the present study is focussed on the analysis of the possibility for firms to actively create and strategically manage (both formal and informal) institutional mechanisms to access and leverage knowledge and creativity which are dispersed in their external environment.

In other terms, the question posed is: "Can firms consider institutional settings as a tool to systematically direct dispersed individual efforts of discovery and invention towards objects (products or processes) of their interest in order to enhance their value creation capacity?".

In order to conduct the proposed analysis and attempt to answer the question posed, the study contained in the rest of the paper is twofold. In the following section, a theoretical framework is elaborated in order to understand the different ways in which institutional contexts influence and direct value creation processes. The framework is aimed to both: describe how institutions may play a role in directing creative efforts towards different objects and goals; and identify a limited number of fundamental dimensions to take in consideration when describing distinct institutional contexts and their effect on value creation processes.

If, on the one hand, the theoretical model proposed illustrates that institutions influence value creation processes, on the other, it does not allow to answer the question: "can firms actively manage fine-grained instruments like institutions or are the latter developed solely through slow social evolution processes?" and "if so, what are the potential advantages and the possible pitfalls entailed by the use of these 'strategic tools'?".

Aimed towards shedding light on the possibility for firms to consider institutional context management as a viable strategic tool to enhance their value creation capabilities, and drawing on case studies from the software industry, the third section uses the dimensions identified in the theoretical framework to conduct a comparative analysis of the different institutional settings within which software products are invented and produced. The analysis of the software industry is particularly interesting for this study as: similar competing software products are contemporarily being invented and produced within notably different institutional settings; it is the theatre of some of the most interesting experiments firms are conducting in institutional context management.

\section{A conceptual framework for the determinants of the value creation process}

The present section sketches out a theoretical framework which renders explicitly the role played by the institutional context in directing individual efforts of discovery and invention. 
EJMBE

27,2

158

Furthermore, it enables to pin point the main dimensions to take into consideration when describing and evaluating distinct institutional settings and their effect on the value creation processes which take place within them.

The theoretical representation proposed is strongly influenced by the Austrian process and subjective view, whilst the notions of value creation processes and institutional contexts are based on conceptual categories elaborated:

(1) within studies regarding the sources of creativity and entrepreneurial behaviour;

(2) with Penrose's (1959) theory of firm growth and, in particular, the distinction she introduced between productive possibilities and productive opportunities; and

(3) as mentioned earlier, with the neo-institutional approach in economics.

The conceptual representation that follows is aimed to identify the multiple layers of reality which tie individual creativity to the value creation performances of the system analysed. In particular, the three levels of analysis considered are:

(1) A micro-level which is composed of the agents that operate within the system analysed and their values, beliefs, knowledge and motivations. This level is focused on agent creativity and the entrepreneurial behaviours which lead to the intuition and implementation of new resource combinations within the system they belong to.

(2) A meso-level which is composed of the social interaction mechanisms which define the nature and characteristics of the institutional context within which specific spheres of economic endeavour take place. These institutional contexts represent the structure within which micro-level agent behaviours occur.

(3) A macro-level which is composed of economic organisations and their outcomes, in terms of value creation performances. The organisations considered are typically firms but, as will be the case in the software industry, may take on other forms such as organised communities of individuals or non-profit foundations.

The firm's capacity to create value crucially rests on the creativity expressed by individual agents regarding products or processes that the firm may commercialise and/or adopt. It is at the subjective level, in fact, that the kind of creativity that leads to the process of finding new solutions to old problems or posing and resolving new problems for the first time takes place. The kind of rationality which distinguishes the entrepreneurial behaviours on which value creation rests presents the following distinctive characteristics: it has an intuitive nature and cannot be represented in Cartesian logical-deductive terms; it implies the capacity to bring a variety of information and knowledge fragments to a new synthesis; and it rests on the ability to foresee the potential value of the new combinations perceived.

In order to comprehend the role institutions play within value creation processes, it is necessary to abandon treating subjective creativity independently from the context in which individuals operate. Given the non-cartesian nature of the intuition at the basis of entrepreneurial behaviours, micro-level analyses regarding value creation are not susceptible of deterministic theorisation. However, following the "general equilibrium" implications of the micro-behaviours of the agents analysed provides a tool for identifying critical structural relationships and parameters that consent to link micro-level studies regarding individual creativity and entrepreneurial behaviours, to the emergent properties of the macro-system.

In strategy research, it is generally accepted that the possibilities to create new resource combinations are determined by the set of opportunities and threats present in the environment in which firms operate. However, Penrose (1959) underscored that these productive possibilities lead to the realisation of new resource combinations only as long as they are perceived, the resources and the capabilities on which they rest are accessible and 
there is a motivation to grasp such opportunities. The combined presence of all three of these conditions is necessary for innovations to take place; if any one of these conditions comes less, new resource combinations remain mere abstract potential developments and do not give way to concrete innovations.

On the basis of this theoretical representation, in order to assess the capacity of different institutional arrangements to enhance innovation, the scrutiny of their effect on the three dimensions underlying value creation opportunities identified by Penrose (1959) - i.e. perception, accessibility and motivation - allows a systematic consideration of both the subjective and the objective aspects necessary to give a balanced evaluation of the distinctive traits of each institutional arrangement. The following section is dedicated to the comparative analysis of the different institutional settings in which software development occurs and their influence on the determinants underlying value creation processes is assessed and discussed.

\section{The strategic management of institutional settings for value creation in the software industry}

The software industry is particularly turbulent and the rhythm at which innovations and readjustments of the sources of competitive advantage occur is notable. It is perhaps because of these characteristics, that the economic endeavour of software development has been for several years the theatre of some of the more interesting experiments firms are carrying out regarding the strategic management of institutional settings aimed to enhance their value creation performances. The observation of these experiments allows to infer the influence institutions exert on the determinants of firm development identified in the section above and, also, to underscore the possible advantages and pitfalls firms face while managing institutional settings strategically.

The software industry, shows the presence of different models of innovation and production which coexist and compete against one another. Each one of these models is characterised by a specific institutional setting that influences the way in which the innovation and production of software occur.

In particular, it is possible to identify the following two software development models which are considered "pure" as they do not share commonalities:

(1) closed producer-oriented innovation processes, which occur within commercial software (or soft and hardware) firms and rest on the definition of institutional mechanisms that consent high levels of value appropriation; and

(2) open user-centred innovation processes, which occur within open-source communities of programmers or non-profit foundations and rest on institutional mechanisms which facilitate value creation processes, but which, on the other hand, do not allow high levels of value appropriation from innovations.

These different institutional contexts have increasingly proven to be able to elicit successful software programming processes within firms or between networks of independent individuals that share a common interest in the development of specific software projects. In fact, open source software (OSS) has proven to be able to perform as well or better than proprietary software in a number of cases[1]. Wang et al. (2012) argued that OSS and free software (FS) projects have a better chance of success if they possess a desirable social network capital and adopt effective strategies. The institutions that characterize each one of these models systematically influence the main determinants underlying the software development processes which occur within them and also affect the nature of the software elaborated. The two "pure" models are described in brief, highlighting the institutional differences between them and the consequences these produce on the development process and on the software obtained. 
EJMBE

27,2

\section{The closed producer-centred model}

This model is typically adopted by commercial software firms. It is defined "closed" because the development process takes place entirely within the firm and is conducted solely by the latter's employees. Software is developed according to engineering principles experimented in manufacturing industries in "a deliberate attempt to transform software from an unstructured service to a product with a guaranteed level of cost and quality" (Cusumano, 1992, p. 467; Cusumano and Smith, 1997).

Amongst the institutions that distinguish this model, the most obvious are the legal protections applied to the software produced. In particular, the software developed belongs to the firm within which the code is written and not to the single programmers. The specific form of IPRs applied to software has varied in time and space, typically they are protected by copyrights or patents. The aim pursued by the definition of such IPRs is to impede free-riding, imitation or replication of the code to which they are applied by external agents. Such protection is also obtained through the distribution of the object code only.

Single programmers are tied to the firm they work for by carefully designed legal contracts. Generally, these contracts clarify that any right they may have on the code they write automatically passes to the firm, that they are tied to secrecy regarding the contents of their work and that they must not create disloyal competition. At times, these contracts may contain mechanisms to stimulate virtuous behaviours - like the re-use of pieces of code. Though it is not possible to generalise regarding the way software production is organised, it tends to adopt principles similar to those found in manufacturing firms. Thus, software production is guided by strong and layered managerial processes, activities and responsibilities that are allocated to a top-down logic and work is conducted within teams. Though this model is characterised by institutional settings similar to those of manufacturing firms, managers often try to stimulate programmer creativity by mimicking various aspects of the hacker culture. This may, for example, entail encouraging a strong tension towards technical excellence and competitive spirit.

The brief description of the main traits of the formal and informal institutions that distinguish the closed model allows to identify a number of ways in which they influence the main determinants of the development processes that take place within this model. It is possible to summarise them as follows:

(1) The perception of productive possibilities:

- is a top-down process - the objectives guiding software development and the main characteristics of the software are defined at the management level (in part this is due to the necessity to coordinate numerous teams working on different pieces of a programme);

- software development is aimed to obtain market success - marketing departments play a crucial role in defining characteristics that a new software must possess based on. analyses regarding competing products and consumer behaviour in target market segments; and

- target markets chosen to orient software development are often those segments which are larger and present higher growth rates or that represent protected niches.

(2) The accessibility of the resources and competences necessary for the implementation of creative intuitions:

- barriers to accessibility are high due to the extended use of IPRs on software produced according to this model;

- new intuitions often infringe on existing IPRs, rendering difficult the implementation of new programmes; 
- strong IPRs force firms to dedicate resources to research the contents of other firm's IPRs before undertaking new development paths; and

- given the interdependence between perception and accessibility, the closed model leads to a division of knowledge within society which, in turn, hinders not only the implementation but also the perception of new development paths.

(3) The motivation driving software development:

- at the single programmer level - is strictly economic and is stimulated through the use of tangible rewards like salary levels, prizes and career advancements; and

- at the firm level - it is strictly economic. Firms aim to obtain rents from the software they develop internally.

\section{The open user-centred model}

This model describes the process underlying the development of OSS and FS[2] in the community and foundation-based projects (O’Mahony and Ferraro, 2007). We refer to it as "open" because it identifies a transparent and open software development process that involves all programmers who are interested and technically able to contribute to the elaboration of a specific programme. Contributing programmers are software users and not employees of the project they participate on a voluntary basis, and do not receive any direct economic reward for their personal efforts towards revealing creative contributions to the OSS project.

This model is, in many ways, opposite to the closed one: it leads to a significant increase in market adoption of OSS, but contemporarily it sacrifices the possibility to obtain rents from the software produced.

The most prominent formal institutions that distinguish this model are the IPRs applied to the software elaborated. Their aim is: to maintain OS/FS open and transparent to all those interested to analyse, use or modify it; to maximise its circulation on the web; and to protect the identity and the reputation of the OS community or foundation which is governing its development (cf. Lerner and Tirole, 2002b; O’Mahoney, 2003; West, 2003; Bogers and West, 2012). Though in reality there are hundreds of specific licenses, there are two archetypes of licences that show the main difference between OSS and FS. In particular, the Berkley Software Distribution (BSD) licence which is typical of the OS adepts and the GNU General Public Licence (GPL) which is typically used for FS (Free Software Foundation, 1989/1991). Both licences allow the free distribution, use and modification of the source code of the software programmes, and they both allow that support, consultancy and training services tied to the software may be sold without restrictions. They differ regarding the possibility for third parties (typically commercial vendors) to add proprietary code to the community's work and privatise it in the attempt to make a profit (offered by the BSD license).

According to the norms of the internal organisation of the OS communities, single programmers maintain the IPRs on the pieces of software they write. Responsibility over the project is allocated according to the contributions made by programmers to the software officially released on the net (cf. Dahlander and O'Mahony, 2011) - and project leaders often tend to be also founders.

The formal institutions of this model reinforce and rest on the hacker culture that pervades the OS programmer community (Raymond, 1999).

The brief description of the main traits of the formal and informal institutions that distinguish the open model is sufficient to identify the ways in which they influence the 
EJMBE

27,2

162 main determinants of the development processes that take place within this model. It is possible to summarise them as follows:

(1) The perception of productive possibilities:

- The programmers whose creative intuitions lead to the development of a new software are geographically dispersed and are not a pre-defined group of individuals. This aspect consents to leverage the knowledge which is disseminated throughout very different socio-economic contexts.

- The knowledge underlying the creative intuitions is not solely technical, programmers are essentially also users of the software they write and, often, pour effort into these projects because they need the programmes.

- The transparency of the development process implies that individuals may contribute to parts of the programme that best fit their skills.

- Given the possibility to download OSS whilst it is being developed and the variety of time-space contexts in which single programmers-users operate, the programmes are run and experimented in a variety of different settings. This facilitates bug individuation and leads to high-quality software.

(2) The accessibility of the resources and competences necessary for the implementation of creative intuitions:

- Barriers to accessibility are deliberately eliminated through the formulation of licences that guarantee the transparency of both the development process and the programmes obtained. The aim is to maximise the accessibility of the code not only to whoever is interested in using it, but also to who is interested to modify it and, therefore, to develop it further.

- The licences used to create interfaces for the interaction between communities, eliminating the risk that existing IPRs of other O/FS communities or foundations may hinder the implementation of new programmes, and thus fostering a climate of trust between communities.

- Often the licences used contribute to the institutionalisation of the relationship between different communities, e.g. through the use of the GPL licence, the GNU community guarantees the fruits of their work to the Linux community.

- The high accessibility of OS/FS, the trust it encourages and the role of meritocracy it supports give way to an "ecology of productive communities".

(3) The motivation driving software development:

- At the single programmer level (cf. Raymond, 1998a,b, 1999; Lakhani and Von Hippel, 2000; Lakhani and Wolf, 2001; Moody, 2001; Torvalds, 2001; Lakhani et al., 2002; Bonaccorsi and Rossi, 2006; Franke et al., 2013) - internal motivations include: the need for the software programme they are developing; the impression that it may be a fun or interesting; the opportunity to learn by working on stimulating programmes and interacting with other top programmers.

- External motivations include: signalling one's technical abilities and increasing one's reputation in the programmer community; the reputation effects of contributing to OS/FS to obtain higher economic compensations on the labour market (cf. Von Krogh et al., 2012; Raymond, 1999; Weber, 2000; Lerner and Tirole, 2002a, b; Hann et al., 2002).

- At the community/foundation level - to protect the identity and the reputation of the community that is developing the software. 
This model describes the context in which firms actively collaborate with the external open-source community on the development of specific software programmes. It is initiated by commercial firms through the definition of new institutional arrangements - i.e., new licenses and other new formal and informal institutions - with the objective of enhancing the firms' innovative capacity by leveraging the creativity dispersed within the external environment, whilst maintaining the capacity to appropriate sufficient value from the firms' activities.

In the attempt to begin to answer the questions: "can firms actively manage fine-grained instruments like institutions or are the latter developed solely through slow social evolution processes?" and "if so, what are the potential advantages and the possible pitfalls entailed by the use of these strategic tools?", we consider the common traits of the experiences matured by some of the most well-known software (or soft and hardware) firms. What follows draws on a re-elaboration of archival data relative to case studies of three software and hardware firms and three pure software firms which have in various ways set up and managed hybrid development models (Stuermer et al., 2009; Cusumano and Yoffie, 1998; Yoffie and Cusumano, 1999; West, 2003; Gabriel and Goldman, 2002; Moody, 2001; Long, 2003), and is supported by several personal interviews conducted with academic and industry representatives. In particular, case studies related to the former firms are: IBM and its successful interaction with the Apache OS community aimed at the development of the WebSphere products; Apple's Darwin project; and Sun Microsystems' management of its Solaris operating system, its OpenOffice suite and its Java programming language. Case studies related to the latter firms include: Netscape and its unsuccessful Mozilla project; and the successful experiences of Oracle and SAP.

The creation of a context within which to collaborate with external programmers on specific development projects implies the careful elaboration of both formal and informal institutions on behalf of the sponsoring firm. The donation of code on the web must be accompanied by carefully designed licenses. Whilst OS/FS licenses are aimed to keep the code transparent, to maintain the reputation and identity of the sponsoring community and to avoid its hijack from third parties, in firm-based OS projects the aim pursued is to manage the contradicting necessities of transparency and control over the code expressed, respectively, by the external community and by the firm. In order to attract external programmers to contribute to the development project, they must feel sufficiently reassured that the firm will not hijack the fruits of their work once they reach a sufficient value. On the other hand, sponsoring firms wish to maintain the possibility to reap at least a part of the economic rents that the software produced could generate. West (2003) (cf. also Balka et al., 2014; Deodhar et al., 2012) underscored that there are basically two fundamental choices firms have to manage these contradicting issues:

(1) open partly - to divide the programmes into layers and to adopt a different license for each layer; rendering some layers completely open, whilst maintaining other layers closed (e.g. the cases of IBM and Apple);

(2) partly open - rendering the whole programme transparent, but applying terms which concede more liberties to the sponsoring firm than is usually the case in OS/FS licenses (SunMycrosystems' SISSL license, and Netscape's Mozilla Public License and its Netscape Public License, for example). The choice of licensing terms is rendered more difficult in the hybrid model due to the asymmetry with which programmers judge OS licenses proposed by firms rather than by communities or foundations[3].

The institutions a firm must manage in order to set up a successful hybrid development model go well beyond licenses. Not only the firm must make sure technical aspects tied to the quality and the modularity of the code released consents programmers to fruitfully feed 
EJMBE

27,2

164

a virtuous internal-external development process, but it must also be able to create a community interested in the project it sponsors. This last necessity involves aspects relative to agent incentives, authority structures and communication mechanisms. Technically, this implies the creation of mailing lists, web sites and newsgroups dedicated to the projects in order to facilitate communication and coordination between internal and external programmers. To obtain sufficient support from external programmers, firms must manage to overcome the mistrust which is generally felt when they show a sincere affinity to the OS initiative and to the hacker culture.

The efficacy with which hybrid models are implemented depends, also, on the firms' capacity to modify their internal organisational culture. There is the necessity to mature a corporate culture that consents to embrace and appreciate external creativity avoiding to fall into a "not invented here" syndrome.

\section{Discussion and conclusion}

The brief description of the building blocks underlying the creation of hybrid development models in the software industry shows that firms are beginning (inevitably) to consider institutional setting definition as a strategic tool which needs to be intentionally managed in order to re-align the social structure in which software development occurs to the contradicting necessities of value appropriation and value creation. The results that firms have obtained through the adoption of this model have not always been positive. The analysis of unsuccessful projects (e.g. Netscape and in many ways also Apple), shows that the creation of valid hybrid models depends both on technical issues (e.g. the valid modular design of the code released, or the frequency of the official updated releases) and, even more crucially, on a deep comprehension of the systemic nature of institutional settings. This last issue implies that it is insufficient to release precious internally developed code with an adequately defined license applied to it. In order to stimulate the creation of a lively community of interacting internal and external programmers, firms must support formal institution management with the creation of a complex network of coherent informal institutions. "Soft" aspects like modifications in the firm's internal culture and the embrace of the "hacker spirit" are proving to be crucial and need to be managed intentionally.

Successful hybrid models consent firms to obtain a number of benefits. In particular: first, the extension of the user base of the firm's products - which is due to the complex of benefits that follows, plus the low cost of the software released and its attractiveness for those users who value being able to control the main traits of their software autonomously; second, an increase in the quality, reliability and stability of the software obtained - thanks to the efficacy of bug identification given by the variety of contexts in which the software is tested during development and the efficiency with which cognitive resources are allocated through transparent development processes; third, the possibility that entirely new directions for the development of software are perceived and implemented - in fact, the high degree of accessibility given by the transparency of the development process, consents to leverage the creativity dispersed in the external context and in some cases this has lead firms to undertake new development paths they had not imagined ex-ante; fourth, an increased integration of the firm's code with other existing complementary or connected software programmes and a boosted portability of the firm's software on various types of hardware; fifth, increased independence from leading software houses on behalf of firms that produce and offer both soft and hardware - thus, tipping the power balance between actors within technological platforms to the advantage of those who have adopted hybrid models; and finally, the creation of a credible communication channel with the external programmer community - this enables the firm to communicate its vision and propose future development paths that play to its strengths, in the attempt to push the market, external programmers and the firm itself to co-evolve harmoniously. 
Though the focus of this paper is limited to the value creation process, it cannot conclude without discussing the effects that institutional setting management has on the firm's capacity to reap rents from its development activities. In fact, the adoption of the hybrid model analysed above influences not only the firm's value creation process, but also inevitably implies the necessity to re-adjust the way the firm appropriates value too. These two aspects underlying the firms' capacity to produce rents and survive are inevitably linked in a trade-off relationship which imposes to mutually adjust their management. The model analysed, shows the firms' deliberate attempt to stimulate a dynamic process of social interaction and communication which may foster higher levels of creativity and innovation. In order to guarantee the necessary accessibility and to sufficiently motivate external programmers towards the perception of a new code, the firm has to surrender the traditional source through which it appropriates value: barriers to the accessibility of the code developed through IPRs.

The adoption of an institutional setting which facilitates dynamic value creation processes suggests, therefore, the need to turn to dynamic mechanisms for value appropriation in parallel. Strategy studies have suggested that IPRs are not the only tool firms possess, and have singled out a number of mechanisms or routes through which firms may appropriate value from their innovations (Von Hippel, 1988; Moser, 2004; Lieberman and Montgomery, 1988; Lippman and Rumelt, 1982; Teece, 1986, 2006; Pacheco-De-Almeida and Zemsky, 2012). In particular, these include: the possession and the protection from imitation or replication of specialized complementary assets from which to draw Ricardian rents; taking advantage of first mover advantages during the lead time which separates the innovating firm from its imitators; relying on the causal ambiguity tied to the tacit dimension of the knowledge underlying the innovation and the complexity of the resource combinations implemented. Of these mechanisms, in the case of the hybrid models discussed above only the first seems effective. Given the transparency of the programmes released in the hybrid models discussed above, the first source of value appropriation seems the most promising.

In the software industry, firms that have successfully adopted hybrid models have had to tackle the value appropriation issue and show the empirical soundness of these considerations. In fact, not only have they tried to maintain at least a part of their capacity to reap rents from choosing "partly open" or "open partly" licensing strategies, but they have also tended to modify their business model in a search for alternative sources from which to appropriate value. Firms have tried to compensate the distinctive elements they lose through their donation on the web both in the phases before and after the code development. In particular, firms have competed on the general architecture of the software (or soft and hardware) offered - by modifying the basic design of the complex information systems they offer - and/or they have focussed on offering turn-key solutions for clients who express complex and sophisticated needs (like IBM has done). Also, firms have been investing in marketing resources, in high brand reputation, in distinctive client services and in application design. Though the solidity of these alternative sources of value appropriation remains to be assessed in the long run, they do illustrate initial attempts that firms are making to compensate the adoption of dynamic value creation processes.

Though this paper focuses on value creation, it cannot conclude without considering that the adoption of the hybrid model analysed inevitably implies the necessity to re-adjust the way the firm appropriates value too. In fact, firms that have successfully adopted hybrid models have tackled the value appropriation not only by choosing "partly open" or "open partly" licensing strategies, but they have also tended to modify their business model in a search for alternative sources from which to appropriate value. In particular, firms have competed on the general architecture of the software (or soft and hardware) offered, and/or they have shifted value appropriation towards service-centred business models (Cusumano et al., 2014).

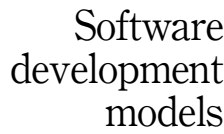

165 
EJMBE

27,2

\section{Notes}

1. Specific examples include the following software programmes: the Linux operating system; the Apache web server; Sendmail; BIND; and the programming language PERL.

2. The distinction between OSS and FS is both ideological and tied to IPRs. In particular, FS adepts (the most prominent of whom is Richard Stallman) are completely closed to interactions with the commercial world, whereas OSS adepts are open to the commercial world. Parallel to these different aptitudes, IPRs applied to FS have a "viral" nature which assures that any derived programmes will continue to be distributed and used according to the same rules, whilst IPRs applied to OSS do not have this "viral" nature.

3. General mistrust in commercial vendor's underlying motivations may explain, for example, the criticisms faced by SunMicrosystem's SISSL license though it is analogous to the license used by the Apache foundation.

\section{References}

Afua, A. and Tucci, C.L. (2012), "Crowdsourcing as a solution to distant search", Academy of Management Review, Vol. 37 No. 3, pp. 355-375.

Allen, R.C. (1983), “Collective invention”, Journal of Economic Behaviour and Organization, Vol. 4 No. 1, pp. $1-24$.

Baldwin, C.Y. and Von Hippel, E. (2011), "Modelling a paradigm shift: from producer innovation to user and open collaborative innovation”, Organization Science, Vol. 22 No. 6, pp. 1399-1417.

Balka, K., Raasch, C. and Herstatt, C. (2014), "The effect of selective openness on value creation in user innovation communities", Journal of Product Innovation Management, Vol. 31 No. 2, pp. 392-407.

Bogers, M. and West, J. (2012), "Managing distributed innovation: strategic utilization of open and user innovation”, Creativity and Innovation Management, Vol. 21 No. 1, pp. 61-75.

Bonaccorsi, A. and Rossi, C. (2006), "Comparing motivations of individual programmers and firms to take part in the open source movement: from community to business", Knowledge, Technology and Policy, Vol. Vol, 18 No. 4, pp. 40-64.

Brown, S.L. and Eisenhardt, K.M. (1995), "Product development: past research, present findings, and future directions", Academy of Management Review, Vol. 20 No. 2, pp. 343-378.

Chatterji, A.K. and Fabrizio, K.R. (2014), "Using users: when does external knowledge enhance corporate product innovation”, Strategic Management Journal, Vol. 35 No. 10, pp. 1427-1445.

Chesborough, H. (2003), Open Innovation: The New Imperative for Creating and Profiting from Technology, Harvard Business School Press, Boston, MA.

Chesborough, H.W. and Appleyard, M.M. (2007), "Open innovation and strategy", California Management Review, Vol. 50 No. 1, pp. 57-76.

Cusumano, M.A. (1992), "Shifting economies: from craft production to flexible systems and software factories", Research Policy, Vol. 21 No. 5, pp. 453-480.

Cusumano, M.A. and Smith, S.A. (1997), "Beyond the waterfall: software development at microsoft", in Yoffie, D.B. (Ed.), Competing in the Age of Digital Convergence, Harvard Business School Press, Boston, MA, pp. 371-412.

Cusumano, M.A. and Yoffie, D.B. (1998), Competing on Internet Time: Lessons from Netscape and its Battle with Microsoft, Free Press/Simon and Schuster, New York, NY.

Cusumano, M.A., Kahl, S. and Suarez, F. (2014), "Services, industry evolution, and the competitive strategies of product firms", Strategic Management Journal, Vol. 36 No. 4, pp. 559-575.

Dahlander, L. and O'Mahony, S. (2011), "Progressing to the center: coordinating project work", Organization Science, Vol. 22 No. 4, pp. 961-979.

Deodhar, S.J., Saxena, K.B.C., Gupta, R.K. and Ruohonen, M. (2012), "Strategies for software-based hybrid business models", The Journal of Strategic Information Systems, Vol. 21 No. 4, pp. 274-294. 
Franke, N., Keinz, P. and Klausberger, K. (2013), “'Does this sound like a fair deal?': antecedents and consequences of fairness expectations in the individual's decision to participate in firm innovation", Organization Science, Vol. 24 No. 5, pp. 1495-1516.

Free Software Foundation (1989/1991), "GNU general public license”, available at: www.gnu.org/ copyleft/gpl; www.fsf.org (accessed 29 November 1991).

Gabriel, R.P. and Goldman, R. (2002), "Open source: beyond fairytales”, available at: www.opensource. mit.edu (accessed 29 November 2002).

Hann, I., Roberts, J., Slaughter, S. and Fielding, R. (2002), "Delayed returns to open source participation: an empirical analysis of the apache http server project", available at: www.idei.asso.fr/Commun/ Conferences/Internet/OSS2002/papiers/Hann (accessed 28 November 2003).

Hayek, F.A. (1945), "The use of knowledge in society", American Economic Review, republished in 1948a, Individualism and Economic Order, Vol. 35, University of Chicago Press, Chicago, IL.

Hayek, F.A. (1948a), "The use of knowledge in society", American Economic Review, Ristampato in 1945, Individualism and Economic Order, Vol. 35, University of Chicago Press, Chicago, IL, pp. 519-530.

Hayek, F.A. (1948b), Individualism and Economic Order, University of Chicago Press, Chicago, IL.

Hayek, F.A. (1960), The Constitution of Liberty, Routledge, London.

Hayek, F.A. (Ed.) (1978), "Competition as a discovery procedure", New Studies in Philosophy, Politics, Economics and the History of Ideas, University of Chicago Press, Chicago, IL, pp. 9-23.

Heiner, R.A. (1983), "The origin of predictable behavior", American Economic Review, December, pp. 560-595.

Heiner, R.A. (1986), “Uncertainty, signal-detection experiments, and modeling behavior”, in Langlois, R.N. (Ed.), Economics as a Process. Essays in the New Institutional Economics, Cambridge Univerity Press, Cambridge, pp. 59-115.

Heller, M.A. and Eisenberg, R.S. (1998), "Can patents deter innovation? The anticommons in biomedical research", Science, Vol. 280 No. 5364, pp. 698-701.

Hodgson, G.M. (1998a), "The approach of institutional economics”, Journal of Economic Literature, Vol. 36 No. 1, pp. 166-192.

Hodgson, G.M. (1998b), "Competence and contract in the theory of the firm”, Journal of Economic Behavior and Organization, Vol. 35 No. 2, pp. 179-201.

Jeppesen, L.B. and Lakhani, K.R. (2010), "Marginality and problem-solving effectiveness in broadcast Search”, Organization Science, Vol. 21 No. 5, pp. 1016-1033.

Lakhani, K.E. and Von Hippel, E. (2000), "How open source software works: free user-to-user assistance”, Working Paper No. 4117, MIT Sloan School of Management, Cambridge, MA.

Lakhani, K.E. and Wolf, R. (2001), Does Free Software Mean Free Labor? Characteristics of Participants in Open Source Communities, Boston Consulting Group Survey Report, Boston, MA, available at: www.osdn.com/bcg

Lakhani, K.E., Wolf, R., Bates, J. and DiBona, C. (2002), "The Boston Consulting Group Hacker Survey Release 0.73”, available at: www.bcg.com/opensource/BCGHackeSurveyOSCON2 4July02v073.pdf (accessed 27 November 2003).

Langlois, R.N. (1984), "Internal organization in a dynamic context: some theoretical considerations", in Jussawalla, M. and Ebenfield, H. (Eds), Information and Communication Economics: New Perspectives, North-Holland, Amsterdam.

Langlois, R.N. (Ed.) (1986a), Economics as a Process: Essays in the New Institutional Economics, Cambridge University Press, Cambridge.

Langlois, R.N. (1986b), "Rationality, institutions and explanation”, in Langlois, R.N. (Ed.), Economics as a Process: Essays in the New Institutional Economics, Cambridge University Press, Cambridge, pp. 225-255. 
EJMBE

27,2

Langlois, R.N. (1986c), "The new institutional economics: an introductory essay", in Langlois, R.N. (Ed.), Economics as a Process: Essays in the New Institutional Economics, Cambridge University Press, Cambridge.

Langlois, R.N. (1992a), "Transaction-cost economics in real time”, Industrial and Corporate Change, Vol. 1 No. 1, pp. 99-127.

Langlois, R.N. (1992b), "External economies and economic progress: the case of the microcomputer industry", Business History Review (High-Technology Industries), Vol. 66 No. 1, pp. 1-50.

Langlois, R.N. (1995), "Transaction costs, production costs, and the passage of time", Working Paper No. 3, Department of Economics, University of Connecticut, Storrs, CT.

Lieberman, M.B. and Montgomery, D.B. (1988), "First mover advantages", Strategic Management Journal, Vol. 9 No. 1, pp. 41-58.

Lepak, D.P., Smith, K.G. and Taylor, M.S. (2007), "Value creation and value capture: a multilevel perspective”, Academy of Management Review, Vol. 32 No. 1, pp. 180-194.

Lerner, J. and Tirole, J. (2002a), "The simple economics of open source", The Journal of Industrial Economics, Vol. 50 No. 2, pp. 197-234.

Lerner, J. and Tirole, J. (2002b), “The scope of open source licensing”, working paper, Harvard Business School, Boston, MA, available at: www.people.hbs.edu/jlerner/simple.pdf

Lippman, S.A. and Rumelt, R.P. (1982), "Uncertain imitability: an analysis of interfirm differences in efficiency under competition", The Bell Journal of Economics, Vol. 13 No. 2, pp. 418-438.

Loasby, B.J. (1983), "Knowledge, learning and enterprise", in Wiseman, J. (Ed.), Beyond Positive Economics?, MacMillan, London, pp. 104-121.

Loasby, B.J. (1986), "Organisation, competition, and the growth of knowledge", in Langlois, R.N. (Ed.), Economics as a Process: Essays in the New Institutional Economics, Cambridge University Press, Cambridge.

Loasby, B.J. (1994), "Organizational capabilities and interfirm relations”, Metroeconomica, Vol. 45 No. 3, pp. 248-265.

Loasby, B.J. (1998), "The organization of capabilities", Journal of Economic Behaviour and Organization, Vol. 35 No. 2, pp. 139-160.

Long, A. (2003), "How firm initiation and control of projects affects open-source development", available at: www.opensource.mit.edu (accessed 28 November 2003).

Merges, R. and Nelson, R. (1994), "On limiting or encouraging rivalry technical progress: the effect of patent-scope decisions", Journal of Economic Behavior and Organization, Vol. 25 No. 1, pp. 1-24.

Meynhardt, T., Chandler, J.D. and Strathoff, P. (2016), "Systemic principles of value co-creation: synergetics of value and service ecosystems", Journal of Business Research, Vol. 69 No. 8, pp. 2981-2989.

Mocciaro Li Destri, A. and Dagnino, G.B. (2005), "The development of the resource-based firm between value appropriation and value creation”, Advances in Strategic Management, Vol. 22, pp. 213-248.

Moody, G. (2001), Rebel Code: The Inside Story of Linux and the Open Source Revolution, Perseus Books Group, New York, NY.

Moser, P. (2004), "What do inventors patent?", Proceedings of the 4th EPIP Conference, What Motivates Inventors to Invent?, Pisa, 2-3 April.

Nelson, R.R. (1998), "The coevolution of technology, industrial structure, and supporting institutions", in Dosi, G., Teece, D.J. and Chytry, J. (Eds), Technology, Organization and Competitiveness: Perspectives on Industrial and Corporate Change, Oxford University Press, Oxford, pp. 47-63.

Nonaka, I. (1988), "Speeding organizational information creation: toward middle-up-down Management", Sloan Management Review, Vol. 30 No. 1, pp. 57-73. 
North, D.C. (1990), Institutions, Institutional Change and Economic Performance, Cambridge University Press, Cambridge.

North, D.C. (1991), "Institutions”, Journal of Economic Perspectives, Vol. 5 No. 1, pp. 97-112.

North, D.C. (1994), "Economic performance through time", The American Economic Review, Vol. 84 No. 3, pp. 359-368.

North, D.C. (1998), "Where have we been and where are we going?", in Ben-Ner, A. and Putterman, L. (Eds), Economics, Values, and Organization, Cambridge University Press, Cambridge, pp. 491-508.

North, D.C. and Thomas, R.P. (1973), The Rise of the Western World: A new Economic History, Cambridge University Press, Cambridge.

O'Mahony, S. (2003), "Guarding the commons: how community managed software projects protect their work", Research Policy, Vol. 32 No. 7, pp. 1179-1198.

O'Mahony, S. and Ferraro, F. (2007), "The emergence of governance in an open source community", Academy of Management Journal, Vol. 50 No. 5, pp. 1079-1106.

Open Source Initiative, "History of the open source effort", available at: www.opensource.org/history (accessed 10 December 2003).

Open Source Initiative, "Open source definition", available at: www.opensource.org/osd (accessed 15 December 2003).

Pacheco-De-Almeida, G. and Zemsky, P.B. (2012), "Some like it free: innovator's strategic use of disclosure to slow down competition", Strategic Management Journal, Vol. 33 No. 7, pp. 773-793.

Penrose, E.T. (1959), The Theory of the Growth of the Firm, John Wiley, New York, NY.

Piller, F. and West, J. (2014), "Firms, users, and innovation", in Chesbrough, H.W., Vanhaverbeke, W. and West, J. (Eds), New Frontiers in Open Innovation, Oxford University Press, Oxford, pp. 29-49.

Polanyi, K. (1957), "The economy as instituted process", in Polanyi, K., Arensberg, C.M., Pearson, H.W., Granovetter, M. and Swedberg, R. (Eds), Trade Market in the Early Empires, republished in Granovetter, M. and Swedberg, R. (Eds), 1992, The Sociology of Economic Life, Westview Press and The Free Press, Boulder, CO, pp. 243-270.

Raymond, E. (1998a), "The Cathedral and the Bazaar", available at: www.tuxedo.org/esr/writings/ cathedral-bazaar/cathedral-bazaar (accessed 28 November 2003).

Raymond, E. (1998b), "Homesteading the noosphere: ownership rights and reputation incentives", available at: www.tuxedo.org/esr/writings/cathedral-bazaar/cathedral-bazaar (accessed 3 December 2003).

Raymond, E. (1999), The Cathedral and the Bazaar: Musings on Linux and Open Source by an Accidental Revolutionary, O’Reillyand Associates, Inc., Sebastopol, CA.

Stuermer, M., Spaeth, S. and Von Krogh, G. (2009), "Extending private-collective innovation: a case study”, R\&D Management, Vol. 39 No. 2, pp. 170-191.

Teece, D.J. (1986), "Innovazione tecnologica e successo imprenditoriale”, L'industria, No. 4, pp. 605-643.

Teece, D.J. (2006), "Reflections on profiting from technological innovation", Research Policy, Vol. 35 No. 8, pp. 1131-1146.

Torvalds, L. (2001), "What makes hackers stick? A.K.A. Linus's law", in Himanen, P. (Ed.), The Hacker Ethic and the Spirit of the Information Age, Secker and Warburg, London, pp. xiii-xvii.

Tuomi, I. (2002), Networks of Innovation. Change and Meaning in the Age of Internet, Oxford University Press, New York, NY.

Von Hippel, E. (1976), "The dominant role of users in the scientific instrument innovation process", Research Policy, Vol. 5 No. 3, pp. 212-239.

Von Hippel, E. (1988), The Sources of Innovation, Oxford University Press, New York, NY.

Von Hippel, E. (1994), 'Sticky information' and the locus of problem solving: implications for innovation”, Management Science, Vol. 40 No. 4, pp. 429-439. 
EJMBE 27,2
Von Hippel, E. and Von Krogh, G. (2003), "The private-collective innovation model in open source software development: issues for organization science", Organization Science, Vol. 14 No. 2, pp. 209-223.

Von Krogh, G., Haefliger, S., Spaeth, S. and Wallin, M.W. (2012), "Carrots and rainbows: motivation and social practice in open source software development”, MIS Quarterly, Vol. 36 No. 2, pp. 649-676.

Wang, J., Yu, M.Y. and Shanker, J. (2012), "Human agency, social networks, and FOSS project success", Journal of Business Research, Vol. 65 No. 7, pp. 977-984.

Weber, S. (2000), "The political economy of open source software", Working Paper No. 140, BRIE, Berkeley University, Berkeley, CA.

West, J. (2003), "How open is open enough? Melding proprietary and open source platform strategies", Research Policy, Vol. 32 No. 7, pp. 1259-1285.

Yoffie, D.B. and Cusumano, M.A. (1999), "Judo strategy: the competitive dynamics of internet time", Harvard Business Review, January-February, pp. 71-81.

\section{Further reading}

BSD License (1998), "Berkeley software distribution license", available at: www.opensource.org/bsdlicense (accessed 23 December 1998).

Cusumano, M.A. (1991), Japan Software Factories: A Challenge to the US Management, Oxford University Press, New York, NY.

Cusumano, M.A. (2004), The Business of Software: What Every Manager, Programmer and Entrepreneur Must Know to Thrive and Survive in Good Times and Bad, The Free Press, New York, NY.

De Laat, P.B. (2005), "Copyright or copyleft? An analysis of property regimes for software development", Research Policy, Vol. 34 No. 10, pp. 1511-1532.

Tallman, R. (1985), "1993, GNU Manifesto", available at: www.gnu.org/gnu/manifesto (accessed 26 December 1985).

Yoffie, D.B. (Ed.) (1997), Competing in the Age of Digital Convergence, Harvard Business School Press, Boston, MA.

\section{Corresponding author}

Giovanna Lo Nigro can be contacted at: giovanna.lonigro@unipa.it

For instructions on how to order reprints of this article, please visit our website: 